\title{
ANDRÉS SANTA CRUZ, PRESIDENTE DE LA CPC: "EL DIÁLOGO FRECUENTE CON LA CENTRAL UNITARIA DE TRABAJADORES NOS HA PERMITIDO AUMENTAR LAS CONFIANZAS".
}

- Frente a las desigualdades que exhibe Chile, especialmente las referidas a la distribución del ingreso, este dirigente de los empresarios cree que es un tema que no se debe dejar pasar. Pero también se debe reconocer que hoy en el país hay menos pobres, menos desempleados, más jóvenes tienen acceso a la educación y más familias pueden optar a créditos o subsidios habitacionales.

En el ámbito de la nueva justicia laboral, considera que su puesta en marcha, al garantizar de manera eficiente los derechos de unos y de otros, ha contribuido a un clima de mayor interacción entre el mundo del trabajo y de los empleadores.

\section{POR ARTURO CASTILLO VICENCIO}

Para el presidente de la Confederación de la Producción y del Comercio (CPC), el independiente Andrés Santa Cruz, los desafíos de cambios que se han implantado en la discusión interna del debate nacional representan muy buenas oportunidades para la sociedad civil. El dirigente empresarial, quien también ocupó la presidencia de la Sociedad Nacional de Agricultura (SNA), cree que las materias laborales y las cuestiones sindicales deben estar en la primera línea de la discusión. Y que, por suerte, nuestra clase política -dice- tiende a actuar con responsabilidad frente a estas situaciones.

Santa Cruz es una persona con una agenda muy apretada. Divide su escaso tiempo entre sus obligaciones gremiales y sus actividades privadas como agricultor, lo que lo obliga a estar en constante movimiento entre su predio de la zona central y las oficinas de la CPC.

No le ha tocado una presidencia fácil (estará al frente de la CPC hasta el año 2015). Las recientes elecciones presidenciales y parlamentarias, con toda la discusión política que implicó, no lograron desmarcarlo de su función primordial, que es la dirigencia de un gremio que puja por una estabilidad social, por el progreso económico y por el bienestar. No en vano ha sido muy crítico en contra de sus propios pares que han dejado un tanto en el baúl de los recuerdos los principios de la responsabilidad social de la empresa y del empresario.

Hoy, la CPC se ha caracterizado por estar en medio del ojo del huracán, enfrentando la contingencia sin eludir los temas más importantes para su sector y para quienes están de alguna y otra manera relacionados con ellos. Por ejemplo, la convivencia con el sindicalismo nacional.

\section{¿Qué nivel de relaciones tiene la CPC con la CUT?}

Tenemos una muy buena relación con la Central Unitaria de Trabajadores. El diálogo frecuente nos ha permitido aumentar las confianzas y reconocer el inmenso peso que tienen las con- 
Arturo Castillo Vicencio/ Andrés Santa Cruz, presidente de la CPC

versaciones con los actores sociales directamente involucrados, especialmente si somos capaces de construir acuerdos.

\section{¿Es un buen nivel o está lejos de lo óptimo?}

Considero que tenemos un buen nivel de relaciones y es nuestro ánimo perseverar en ellas.

\section{Ustedes firmaron una "Declaración de Voluntades” con la CUT hace un año. ¿Qué significado le atribuye a ello?}

Se trató de un importante hito, porque las conversaciones partieron el año 2011, cuando los estudiantes y otras organizaciones sociales llevaban muchos días tratando de colocar sus demandas a través de movilizaciones sociales en la calle; y nosotros, junto con la CUT, mostramos que con diálogo directo y respetuoso existen otras formas de superar las diferencias y generar puntos de encuentro. En buenas cuentas, ambos demostramos que los actores sociales somos fundamentales para alcanzar acuerdos, a través de un diálogo franco, sin vetos, tratando las más diversas materias, por complejas que éstas sean, ya que somos los directamente involucrados y sabemos "dónde nos aprieta el zapato".

En relación a lo anterior, ¿estima usted que es posible y conveniente establecer el mecanismo del Dialogo Social actualmente en Chile?

El diálogo social directo, libre, informado y frecuente ya existe entre la Confederación de la Producción y del Comercio y las distintas centrales de trabajadores del país, con quienes han sido múltiples las reuniones que hemos sostenido. Respecto a la idea de institucionalizar el diálogo, pienso que es una alternativa que se puede estudiar, pero lo importante es no imponer a los actores sociales una súper estructura que afecte la fluidez que hoy tienen nuestras conversaciones.

\section{LEGISLACIÓN LABORAL}

\section{¿Cuál es la opinión de la CPC en relación a legislación laboral actualmente vigente en Chile?}

Pensamos que debe perfeccionarse con el propósito de generar más espacios para los acuerdos de las partes en materia de distribución de la jornada y trabajo por horas, con el objetivo que aumente la participación laboral, en especial de las mujeres y los jóvenes.

\section{Si hay que hacerle reformas, ¿cuáles serían ellas?}

Aparte del tema antes referido, pienso que es urgente mejorar el vigente sistema de capacitación, para que exista un efectivo reconocimiento de estudios y complementariedad entre los distintos niveles educativos -escuelas, institutos técnicos y universidades-, y para que las ofertas educativas estén alineadas con las ofertas de empleo de las empresas.

\section{¿Cree usted que el sistema previsional de las AFP e Isapres requieren cambios?}

Todos los sistemas deben adecuarse a las realidades cambiantes de la sociedad. En este sentido, los importantes cambios demográficos que se están produciendo en Chile -menos nacimientos y más sobrevida de la población; nuevas patologías de salud y otras que han sido superadas, entre otros-, exigen ajustes que permitan que los sistemas de salud y pensiones sean acordes a los tiempos que corren. 


\section{¿Cuáles serían?}

Hoy son muchas las propuestas que se escuchan para mejorar el sistema de pensiones. Yo sólo mencionaría un par que me parecen bastante evidentes: por una parte, es necesario aumentar la edad de jubilación de la población, porque está comprobado que hoy se vive más tiempo. Por otra parte, es necesario aumentar los aportes que actualmente hacemos, que alcanzan el 10\% de las remuneraciones con un tope, porcentaje bajísimo si se compara con lo vigente en los diferentes sistemas en la gran mayoría de los países. Estos son dos cambios que requiere nuestro sistema previsional para atacar el fondo del problema, que consiste en mejorar el monto de las pensiones de quienes jubilen y permitirles que tengan una vida digna en sus últimos años.

\section{¿Qué opinión tiene usted acerca el tema del Multirut?}

Aunque se trata de una práctica legítima de las empresas, que les permite organizarse de la forma que estiman más productiva para enfrentar la competencia, cuando el Multirut pasa a llevar derechos laborales de los trabajadores, sean éstos individuales o colectivos, entonces sí que tenemos un problema grave, que debe ser corregido, de manera que nunca una práctica comercial o productiva afecte los derechos legítimos de sus trabajadores, sean éstos de carácter individual o colectivos.

\section{Cuando se señala que Chile tiene altos índices de injusticia social, referido a la distribución del ingreso, ¿qué sentimiento lo embarga al respecto?}

Como chileno, este tema me preocupa mucho y claramente falta mucho por avanzar. Pero también es innegable que la sociedad chilena ha experimentado grandes cambios, con importantes progresos en lo económico y social.

\section{¿Cuáles, por ejemplo?}

Algunos logros notables son la disminución de la pobreza en 30 puntos desde 1987 a la fecha; un alza significativa del ingreso de las personas, que sitúa a Chile como el segundo país que más aumentó su PIB per cápita después de China entre 1985 y 2013; la ampliación de la cobertura de la educación superior desde 249.482 estudiantes en 1990 a 1.127.200 en 2012; se ha mejorado de manera sustantiva el acceso al crédito, a la vivienda, a la salud, etc. No obstante, es necesario continuar con las políticas que fomentan el crecimiento, el empleo y el emprendimiento, para que los beneficios económicos, sociales y espirituales del desarrollo efectivamente lleguen a todos los chilenos.

\section{¿Le parece bien el sistema de reparto de utilidades de las empresas actualmente vigente en Chile? ¿Le haría cambios? ¿Cuáles serían estos?}

El actual sistema de reparto se concentra en la figura de la gratificación legal, que como está formulada en la ley, estimula el reparto mensual de un monto de dinero más que una distribución anual ligada a los resultados de la empresa. Esto ya está internalizado por la gran mayoría de los trabajadores y las empresas. Creo, sin embargo, que hoy existen otras formas de reparto de las utilidades de las empresas que no suelen estar reconocidas como tales, pero que al final del día permiten que los trabajadores perciban mayores ingresos cuando a la empresa le va bien. Me refiero, por ejemplo, a las remuneraciones variables, que contemplan bonos por desempeño o cumplimiento de metas, entre otras múltiples figuras. De modificar el sistema vigente de gratificaciones, lo haría para generar nuevas alternativas en la ley, adicionales a las existentes, para que las partes puedan definir la mejor forma de distribuir las utilidades de la empresa entre los trabajadores que contribuyeron a su generación. 
Arturo Castillo Vicencio/ Andrés Santa Cruz, presidente de la CPC

\section{¿Cómo se puede superar esa desigualdad?}

Estoy convencido que la educación de calidad desde los primeros años de vida es la mejor manera de lograr una mayor igualdad en la sociedad. La desigualdad se supera también mejorando la participación laboral, y mejorando la pertinencia de la educación y la capacitación para que sean factores vitales en los incrementos de la productividad. Generar las condiciones para que eso ocurra es el gran reto país.

\section{SINDICATOS, NEGOCIACIÓN COLECTIVA Y HUELGAS}

\section{¿Cree que debe mantenerse el reemplazo de los trabajadores durante una huelga?}

Los reemplazos durante la huelga no son exclusivos de Chile, existen en otros países con niveles de desarrollo superior o similar al nuestro, tales como Estados Unidos, Canadá, Reino Unido, Francia, México y Brasil, y se trata de una eficiente alternativa para evitar daños sustantivos que afecten la sostenibilidad de las empresas. Pero no queremos que se piense que ésta es una herramienta destinada a minar la negociación colectiva y la actividad sindical, por lo que consideramos que hay espacio para perfeccionar la regulación para que ninguno de los actores laborales la vea con desconfianza.

\section{¿Qué opina del sindicato único por empresa?}

Pienso que los trabajadores deben decidir libremente la forma como se organizan, cuando estimen que ello es relevante. Ahora bien, si ellos libremente optan por organizarse en un sindicato único, es su elección y me parece muy bien. En todo caso, debo señalar que con lo que no podemos estar de acuerdo es con la imposición de la sindicalización o de la pertenencia a un determinado sindicato para trabajar, ya se trate de un sindicato único o no, porque ello atenta contra las libertades básicas de la persona humana y -por cierto- también contra la libertad sindical, que es la libertad para sindicalizarse pero también para no hacerlo, si así lo estima la persona, y nadie puede estar facultado para exigirle lo contrario.

\section{LA NUEVA JUSTICIA DEL TRABAJO}

\section{¿Cómo evalúa la CPC los resultados que han arrojado hasta ahora la puesta en marcha del nuevo sistema procesal laboral? \\ El procedimiento laboral vigente logró que la justicia sea más expedita y eso es un gran avance. Pienso que ese hecho ha generado una importante señal al mundo del trabajo, en cuanto a que hay que tratar de mejorar las relaciones laborales y cumplir la legislación laboral para evitar enfrentarnos a conflictos.}

¿Cuáles cree usted que han sido sus principales impactos en las relaciones entre empresarios y trabajadores?

Lo que citaba antes, pienso que cuando todos sabemos que la justicia opera de manera oportuna, los incentivos son mayores para que mejore el cumplimiento de la legislación laboral.

\section{¿Contribuye o no el nuevo sistema procesal laboral a la armonía entre empresarios y trabaja-} dores?

Contribuye, da más certezas y garantiza los derechos de las partes. 


\section{¿Le preocupa la reforma tributaria en relación a las inversiones y al empleo?}

Nosotros entendemos que el tema tributario es importante porque determina el tamaño del Estado y los servicios que éste puede proveer, y desde el punto de vista de la empresa es un elemento sustantivo para su desarrollo y sostenibilidad, porque se relaciona de manera directa con sus costos operativos, acceso al crédito, capacidad de contratación y acceso a inversiones, como también está directamente relacionado con la existencia de mecanismos que incentiven el ahorro y la inversión de las empresas. Por tanto, es un elemento esencial en el funcionamiento de la sociedad, y como tal, cualquier anuncio de cambio de las reglas en esta materia hay que analizar con mucho cuidado los múltiples impactos que puede generar para las empresas que representamos y el empleo que ellas proveen. En este sentido, valoramos mucho que se despejen sus alcances y contenidos en el menor tiempo posible y así evitar eventuales incertidumbres. Ya lo he dicho antes, los impuestos no son neutros, por lo tanto a la hora de realizar cambios a la estructura tributaria, es fundamental evaluar bien cuáles son las necesidades del país, cuantificarlas, procurar la máxima eficiencia en el gasto y buscar que los impuestos tengan el menor impacto en el crecimiento, las inversiones y el empleo.

\section{¿Se siente optimista frente a los desafíos del futuro o, como dicen los campesinos, mira con ojo inquieto si la lluvia tarda?}

Creo en la estabilidad de las instituciones de nuestro país, en nuestra fuerte cultura democrática y republicana, y en la seriedad de los dirigentes políticos a quienes les ha correspondido la responsabilidad de regir los destinos del país. Por ello, veo el futuro con optimismo, pero también sé que como actor social estamos frente a un momento histórico y una nueva realidad social que nos exige una gran responsabilidad de contribuir con nuestros aportes al debate y construcción de políticas públicas que apunten a continuar en la senda del crecimiento y desarrollo que no hemos fijado como país y que traerá mayor bienestar a todos los chilenos. 